\title{
Construction of a Dicotomous Key for Common Local and Imported Timber Species in Sri Lanka
}

\author{
Muthumala C.K. ${ }^{{ }^{*}}$ and Amarasekara H.S. ${ }^{2}$ \\ ${ }^{I}$ State Timber Corporation, Sampathpaya, Battaramulla \\ ${ }^{2}$ Department of Forestry and Environmental Science, Faculty of Applied Sciences, \\ University of Sri Jayewardenepura, Nugegoda, Sri Lanka \\ *ck_muthumala@yahoo.com
}

\begin{abstract}
Proper timber identification mechanism is essential today than ever before as lesser known local and imported timber species are coming to timber market in present. In Sri Lanka there are over 400 different timber species of commercial use, which show a remarkably wide range of variation in their physical properties as well as their anatomical structures. Hence timber identification is a highly important task to confirm its authenticity. Scientific wood identification is based on microscopic evaluation of anatomical properties.
\end{abstract}

The objective is of this research is to develop a timber identification key for common local and imported timber species used in Sri Lanka to facilitate scientific identification of timber species based on anatomical features in IAWA (International Association of Wood Anatomist) list of 1989.

Timber samples of local and imported timber species were collected from various floristic regions in Sri Lanka. Authentic timber samples were collected from Research Division of the State Timber Corporation. Transverse section (T.S), Radial Longitudinal Section (R.L.S.) and Tangential Longitudinal Section (T.L.S.) were obtained using the Microtome. Microscopic slides were prepared for sixty seven timber species and photographic representations and anatomical details were presented. Anatomical features of rays, parenchyma and vessels were studied. Tangential vessel diameter and ray height were also measured. Values of the mean vessel diameter were categorized according to IAWA: category $1(<=50 \mu \mathrm{m})$, Category 2 , $(50-100 \mu \mathrm{m})$, Category $3(100-200 \mu \mathrm{m})$ and Category $4(>=200 \mu \mathrm{m})$.

The highest mean vessel diameter value was observed in Garcinia spp (Kandis) and second highest value was observed in Azadirachta indica (Margosa) timber species. The lowest Mean Vessel Diameter value was observed in Elaeodendron glaucum (Neralu) timber species.

Specific gravity values were taken from previous research and publications. Specific gravity are categorized three categories according to IAWA features: low $(<=0.40)$, medium $(0.40$ $0.75)$ and high $(>=0.75)$. The highest basic specific gravity value was observed in Diospyros ebenum (Ebony) (1.12) and second highest value was observed in Palu (1.1) timber species. The lowest basic specific gravity values were observed in Lunumidella and Rukattana timber species.

Mean ray height of 67 timber species were measured using Micrometrics SE premium 4 software available at research division in the State Timber Corporation.

Proceedings of the International Forestry and Environment Symposium 2013 of the Department of Forestry 
A dichotomous key on timber identification was prepared using 56 common local timber species and 11 major imported timber species mostly used in Sri Lanka to facilitate scientific identification of timber species based on anatomical features of IAWA (International Association of Wood Anatomist) List 1989.

Keywords: Dicotomous key, Local timber, Imported timber, Scientific identification 